\title{
Profil Klinis dan Keluaran Penyakit Jantung Reumatik pada Anak yang Menjalani Bedah Katup
}

\author{
Rahmat B Kuswiyanto, Sukman T Putra, ${ }^{* *}$ Najib Advani, ${ }^{* *}$ Mulyadi M Djer, ${ }^{* *}$ Rubiana \\ Sukardi, ${ }^{* * *}$ Jusuf Rachmat*** \\ * Bagian Ilmu Kesehatan Anak RSUP Hasan Sadikin, Fakultas Kedokteran Universitas Padjadjaran, \\ Bandung \\ "Departemen Ilmu Kesehatan Anak, RSUP Cipto Mangunkusumo, Fakultas Kedokteran Universitas \\ Indonesia, Jakarta. \\ *** Pelayanan Jantung Terpadu, RSUP Cipto Mangunkusumo, Jakarta
}

Latar belakang. Penyakit jantung reumatik merupakan kelainan jantung didapat penyebab kesakitan dan kematian terbanyak pada anak di Indonesia. Bedah katup pada anak dengan penyakit jantung reumatik jarang dilakukan.

Tujuan. Untuk mengetahui profil klinis dan keluaran bedah katup pada anak dengan penyakit jantung reumatik.

Metode. Penelitian secara retrospektif dilakukan pada 28 anak dengan penyakit jantung reumatik yang menjalani bedah katup di RSUPN Cipto Mangunkusumo selama tahun 2003 sampai 2009. Data dikumpulkan dan dicatat berdasarkan catatan medis berupa profil klinis sebelum operasi, umur saat operasi, jenis kelamin, status klinis, dan jenis operasi, serta data ekokardiografi berupa kelainan katup dan fungsi ventrikel. Sedangkan keluaran berupa komplikasi pascaoperasi, lesi residual dan fraksi ejeksi, fraksi pemendekan serta dimensi akhir diastolik ventrikel kiri seminggu pascaoperasi.

Hasil. Umur rerata saat operasi 13,9 (SD 2,7) tahun; anak laki-laki dan perempuan sama banyak. Status klinis praoperatif fungsional kelas III dan kelas IV masing-masing terjadi pada 13 dan 9 anak. Regurgitasi mitral berat didapatkan pada 75\% anak. Perbaikan katup mitral dilakukan pada 16, penggantian katup mitral pada 8, dan penggunaan katup ganda pada 4 anak. Tiga anak mengalami komplikasi berupa perdarahan, efusi pleura, dan sepsis, sedangkan satu orang meninggal. Lesi residual pascaoperasi didapatkan pada 11 anak, berupa regurgitasi dan stenosis mitral ringan, dan satu anak dengan paravalvular leak. Tidak didapatkan perbedaan yang bermakna dalam fraksi ejeksi, fraksi pemendekan dan dimensi akhir diastolik ventrikel kiri sebelum dan seminggu sesudah operasi.

Kesimpulan. Bedah katup pada anak dengan penyakit jantung reumatik mempunyai keluaran yang baik, dengan angka kematian dan komplikasi yang rendah. Pemantauan lebih lanjut diperlukan untuk menilai keluaran jangka panjang. Sari Pediatri 2011;13(3):200-6.

Kata kunci: bedah katup, penyakit jantung reumatik pada anak

\footnotetext{
Alamat korespondensi:

Dr. Rahmat Budi K, SpA. Bagian Ilmu Kesehatan Anak FK Universitas Padjadjaran/RSUP Hasan Sadikin Bandung Jln. Pasteur no 38 bandung.

E-mail: rahmat_budi_k@yahoo.co.id
} 


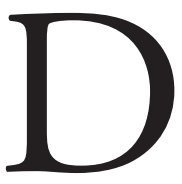
emam reumatik (DR) dan penyakit jantung reumatik (PJR) merupakan kelainan jantung didapat terbanyak penyebab kesakitan dan kematian pada anak, remaja, dan dewasa muda di Indonesia. Insidens DR dan prevalensi PJR sampai saat ini tidak banyak berubah dibandingkan sepuluh tahun yang lalu, yaitu berkisar 0,3-0,8 per 1.000 anak sekolah dengan rentang usia 5-15 tahun. ${ }^{1}$

Eksaserbasi akut DR menyebabkan beberapa pasien mengalami PJR kronik dengan kerusakan katup jantung yang membutuhkan pembedahan. Intervensi bedah pada kasus PJR dewasa telah banyak dilaporkan dengan hasil yang memuaskan, tetapi pada anak masih memperlihatkan beberapa masalah, seperti durabilitas hasil operasi dan teknik operasi yang lebih sulit.-5 Perbaikan katup pada anak lebih dipilih dibandingkan dengan penggantian katup bila secara teknis lebih memungkinkan, namun pengalaman pada anak dengan PJR terbatas. Tujuan penelitian melakukan evaluasi profil klinis dan keluaran bedah katup pada anak PJR di RSUPN Cipto Mangunkusumo.

\section{Metode}

Penelitian retrospektif dilakukan pada 28 anak PJR yang menjalani bedah katup pada periode tahun 2003 sampai 2009 di RSUPN Cipto Mangunkusumo Jakarta. Berdasarkan pada rekam medis dikumpulkan dan dicatat profil klinis yang mencakup umur saat operasi, jenis kelamin, kelas fungsional praoperatif berdasarkan pada klasifikasi New York Heart Association (NYHA) patologi kelainan katup, fraksi ejeksi, fraksi pemendekan, dimensi akhir diastolik ventrikel kiri dan jenis operasi yang dilakukan. Keluaran yang dievaluasi adalah komplikasi pascaoperasi, jumlah kematian, lama perawatan di ruang intensif, frekuensi reoperasi dan hasil ekokardiografi yang mencakup evaluasi hasil bedah katup dan fungsi ventrikel kiri berupa fraksi ejeksi, fraksi pemendekan serta dimensi akhir diastolik ventrikel kiri. Data dicatat dan disajikan secara deskriptif dan untuk membandingkan fraksi ejeksi, fraksi pemendekan dan dimensi akhir diastolik ventrikel kiri sebelum dan sesudah operasi digunakan uji T dengan tingkat kemaknaan (p) sebesar 0,05.

\section{Hasil}

Pada periode tahun 2003 sampai 2009 didapatkan 28 anak PJR reumatik yang menjalani pembedahan katup mitral dengan umur median saat dilakukan pembedahan jantung adalah 13,9 (SB 2,7) tahun. Anak laki-laki dan perempuan masing-masing 14 orang. Semua anak pada saat datang memperlihatkan gejala dan tanda gagal jantung. Berdasarkan klasifikasi NYHA, terdapat 6 anak fungsional kelas II, 13 anak kelas III, dan 9 anak kelas IV, tidak ada anak yang termasuk dalam klasifikasi fungsional kelas I. Pada

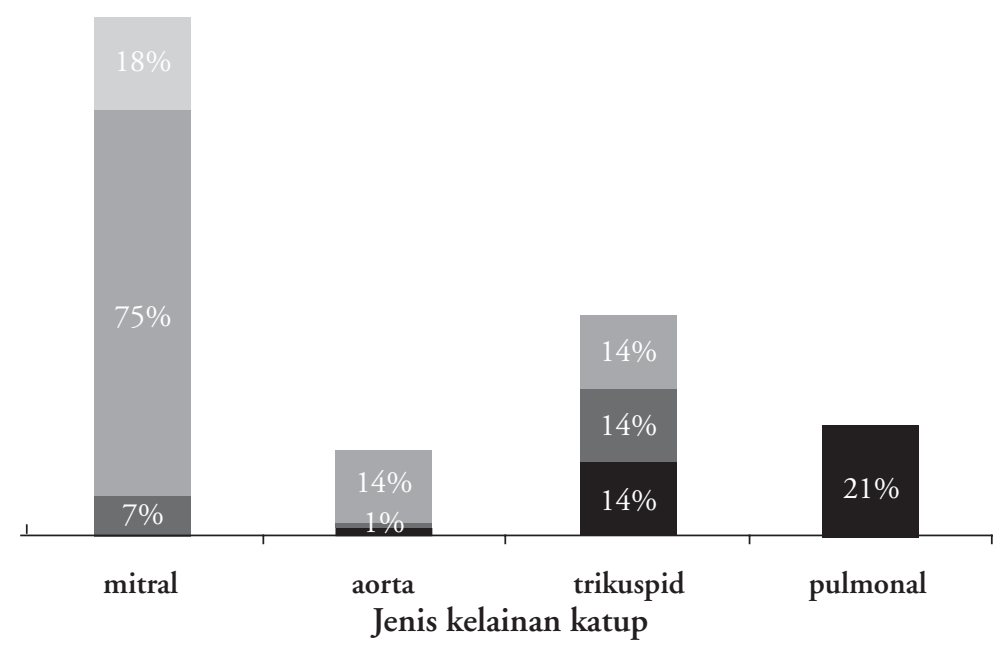

campuran

regurgitasi berat

regurgitasi sedang

regurgitasi ringan

Gambar 1. Kelainan katup pada anak dengan penyakit jantung reumatik sebelum dilakukan operasi berdasarkan pada pemeriksaan ekokardiografi 
kardiomegali didapatkan pemeriksaan foto dada pada semua anak. Semua anak memperlihatkan irama sinus pada elektrokardiografi, kecuali satu anak dengan atrial fibrilasi. Terdapat empat orang anak dengan riwayat endokarditis sebelum dilakukan operasi.

Pada pemeriksaan ekokardiografi regurgitasi mitral berat merupakan kelainan terbanyak (75\%). Dua anak dengan regurgitasi mitral sedang dan 5 anak dengan kelainan campuran berupa regurgitasi dengan stenosis. Regurgitasi aorta berat didapatkan pada 4 anak, 1 anak dengan regurgitasi aorta sedang, dan 3 anak dengan regurgitasi ringan. Regurgitasi trikuspid berat, sedang, dan ringan masing-masing didapatkan pada 4 anak, Sebagian besar katup pulmonal masih normal, hanya 6 anak yang memperlihatkan regurgitasi ringan (Gambar 1).

Fungsi ventrikel kiri praoperasi memperlihatkan fraksi ejeksi dan fraksi pemendekan dengan rerata yang normal, namun dimensi ventrikel kiri pada akhir diastolik sudah mengalami peningkatan. Pemeriksaan ekokardiografi seminggu pascaoperasi memperlihatkan regurgitasi mitral ringan pada 4 anak, stenosis ringan 5 anak, stenosis dengan regurgitasi ringan 2 anak, dan 1 anak dengan paravalvular leak. Tidak didapatkan perbedaan bermakna fungsi ventrikel kiri sebelum dan seminggu setelah operasi (Tabel 1).

Jenis operasi terbanyak adalah perbaikan katup mitral yang dilakukan pada 16 anak (57\%). Delapan orang anak menjalani penggantian katup mitral. Empat orang anak menjalani penggantian katup ganda karena regurgitasi berat pada katup mitral dan aorta. Enam orang anak menjalani anuloplasti trikuspid karena regurgitasi berat pada katup trikuspid (Gambar 2).

Rerata cross clamp time adalah 95,5 (SB 33,9) menit dan bypass time 123,3 (SB 43,7) menit. Median hari perawatan di ruang intensif selama 2 hari dengan interval 1 sampai 5 hari. Komplikasi pascaoperasi terjadi pada 3 anak (11\%), berupa efusi pleura, perdarahan, dan sepsis. Satu anak perempuan berumur 13 tahun dengan gagal jantung berat, atrial fibrilasi

Tabel 1. Fungsi ventrikel kiri pada anak dengan penyakit jantung reumatik

\begin{tabular}{lcccc}
\hline Fungsi ventrikel & Praoperasi & Pascaoperasi & $\mathrm{p}$ & $95 \% \mathrm{CI}$ \\
\hline EF $(\%)$ & $61,5 \pm 10,4$ & $60,3 \pm 9,9$ & 0,53 & $-2,5-4,9$ \\
FS $(\%)$ & $32,7 \pm 5,0$ & $34,2 \pm 5,6$ & 0,18 & $-3,5-0,68$ \\
LVEDD $(\mathrm{mm})$ & $50,8 \pm 7,3$ & $47,9 \pm 7,4$ & 0,06 & $-0,18-5,9$ \\
\hline
\end{tabular}

Keterangan: EF: ejeksi fraksi ventrikel kiri, FS: fraksi pemendekan ventrikel kiri, LVEDD: dimensi diastolik akhir ventrikel kiri

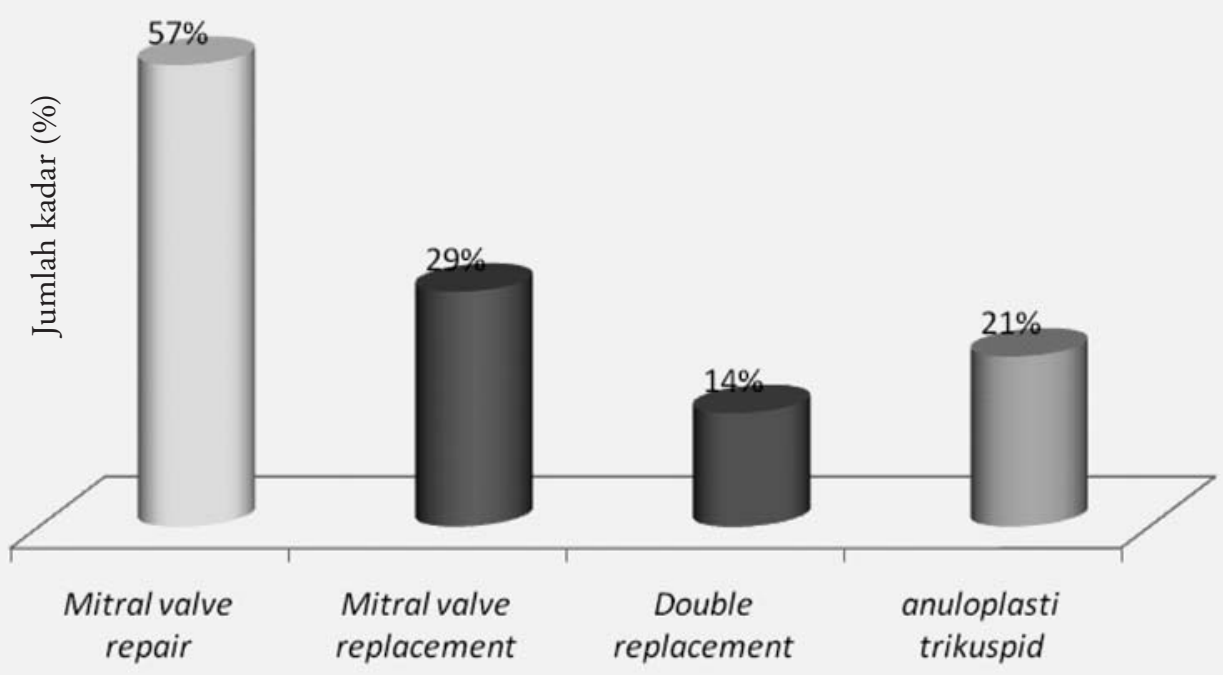

Jenis operasi

Gambar 2. Jenis operasi pada anak dengan penyakit jantung reumatik 
refrakter, dan mitral stenosis berat meninggal tidak lama setelah operasi emergensi karena perburukan keadaan klinis. Satu anak menjalani operasi ulang karena terjadi perdarahan.

\section{Pembahasan}

Selama periode penelitian ( 7 tahun) didapatkan 28 anak PJR yang menjalani bedah katup. Angka tersebut tidak menggambarkan insidens bedah katup pada anak PJR di Indonesia yang sesungguhnya sebab hanya berdasarkan pada laporan dari satu senter saja. Insidens pembedahan pada anak PJR berbeda di berbagai negara. Amerika melaporkan 7\%, ${ }^{6}$ sementara di Australia mencapai $18 \%,{ }^{7}$ dan Libanon 31\%. ${ }^{8}$ Perbedaan tersebut disebabkan oleh perbedaan pelayanan kesehatan dan pemberian profilaksis sekunder setelah serangan demam reumatik. Berkurangnya kejadian serangan ulang dapat mencegah kerusakan katup lebih lanjut sehingga tidak diperlukan tindakan operasi. Pada pasien kami sebagian besar mendapatkan injeksi benzatin penisilin untuk profilaksis sekunder, mengingat tingkat kepatuhan yang rendah dan tidak ada biaya yang lebih murah namun efektifitasnya tinggi. Sebagian besar pasien yang menjalani operasi telah menunjukkan gejala klinis, berasal dari sosial ekonomi dengan tingkat kepatuhan untuk kontrol yang rendah sehingga datang ke rumah sakit pada tingkat lanjut. Upaya peningkatan sosial ekonomi, pendidikan kesehatan, pelayanan kesehatan yang lebih baik dan terjangkau merupakan masalah mendasar yang harus diupayakan untuk mengatasi masalah ini. Walaupun demam reumatik banyak ditemukan pada masyarakat dengan sosial ekonomi rendah dan negara berkembang, namun laporan kejadian luar biasa di Amerika menunjukkan semua lapisan masyarakat dapat terkena, ${ }^{6}$ hal tersebut menggambarkan masih diperlukan diagnosis yang akurat, pengobatan, dan surveilans yang baik untuk melihat gejala sisa lebih lanjut yang akan berpengaruh terhadap angka kejadian pembedahan.

Usia rerata pada saat dilakukan operasi pada penelitian kami 13,9 tahun, tidak berbeda banyak dari beberapa laporan terdahulu, dengan median umur 11 sampai 12 tahun. ${ }^{6,9-11}$ Laporan dari India menyatakan umur termuda 2 tahun, kondisi yang lebih mungkin terdapat pada kelainan mitral bawaan dibandingkan dengan PJR. ${ }^{9,10}$ Demikian pula kejadian jenis kelamin, serupa dengan penelitian sebelumnya anak laki-laki tidak berbeda banyak dengan anak perempuan. ${ }^{6,9,10}$

Kelainan patologi terbanyak pada penelitian kami adalah mitral regurgitasi. Temuan tersebut tidak berbeda berdasarkan pada beberapa laporan patologi katup pada anak PJR di berbagai negara, sedangkan pada orang dewasa kelainan terbanyak adalah stenosis mitral. ${ }^{4,6,9-11}$ Frekuensi kelainan katup aorta pada anak PJR lebih sedikit dibandingkan dengan kelainan pada katup mitral, sekitar 25\%-30\%. ${ }^{3}$

Inflamasi pada jaringan katup menyebabkan edema pada korda tendinea dan daun katup. Gangguan penutupan katup awalnya terjadi akibat degenerasi hialin yang membentuk veruka pada tepi katup. Lama kelamaan terjadi fibrosis dan kalsifikasi pada katup. Pada umumnya stenosis terjadi 20 sampai 40 tahun kemudian karena proses jaringan parut, ${ }^{5}$ namun kami mendapatkan lesi stenotik pada anak di bawah 15 tahun. Kejadian tersebut dapat disebabkan oleh kerusakan yang terjadi cukup luas dan cepat, akibat profilaksis yang tidak adekuat, atau tingginya transmisi infeksi streptokokus berulang yang tidak mendapat pengobatan tepat. Endokarditis pada beberapa kasus juga menggambarkan kurangnya upaya pencegahan endokarditis pada anak PJR. Empat pasien mengalami regurgitasi aorta berat yang memerlukan penggantian katup. Empat anak menjalani trikuspid anuloplasti oleh karena regurgitasi berat. Kelainan katup trikuspid jarang terjadi mungkin karena operasi dilakukan pada tahap PJR lebih awal sebelum terjadi stenosis berat dan hipertensi pulmonal.

Durasi operasi relatif lebih lama dibandingkan dengan laporan lain, namun angka kematian serta komplikasi rendah, dan lama perawatan di ruang intensif singkat. Laporan lain tidak jauh berbeda dengan angka kematian berkisar 2\%-5\% dan komplikasi di bawah $10 \%$, pada pemantauan lebih lanjut kejadian operasi ulang bervariasi pada berbagai senter. ${ }^{6,9-11,12}$ Penelitian retrospektif dan jumlah subjek yang terbatas, waktu pemantauan yang pendek menyebabkan kesulitan pada penilaian lebih lanjut seperti operasi ulang, merupakan keterbatasan penelitian. Evaluasi lebih lanjut diperlukan untuk mengetahui outcome jangka panjang.

Tujuan perbaikan katup pada anak PJR untuk menghilangkan regurgitasi dan dilakukan sebelum timbul gejala klinis dan disfungsi ventrikel kiri. Pada sesi kasus yang kaki laporkan didapatkan hasil yang cukup baik, terlihat dari pemeriksaan 
ekokardiografi pascaoperasi, namun masih diperlukan evaluasi selanjutnya untuk melihat outcome jangka panjang dan keperluan re-operasi. Perbaikan katup merupakan prosedur pilihan pada anak sebab penggantian katup mempunyai angka kematian yang lebih tinggi dibandingkan dengan dewasa. Hasil operasi berkaitan dengan masalah ukuran pada katup pengganti, pemberian antikoagulan jangka panjang, degenerasi bioprostesis lebih cepat terjadi, risiko tinggi terjadi endokarditis, penurunan fungsi ventrikel, dan penurunan angka harapan hidup, ${ }^{13-18}$ Perbaikan katup mempunyai angka kegagalan yang lebih tinggi dan secara teknis lebih sulit dibandingkan dengan penggantian katup karena kelainan yang lebih kompleks seperti deformitas daun katup, kombinasi kelainan stenosis dan regurgitasi serta keterbatasan pergerakan katup, sehingga meningkatkan frekuensi re-operasi. Selain itu penilaian pascareparasi juga lebih sulit dan serangan ulang demam reumatik membuat hasil reparasi juga kurang stabil. ${ }^{15,16,18}$ Hasil penggantian katup pada anak tidak sebaik reparasi dengan angka kematian 19\%, sehingga reparasi merupakan pilihan pada anak, namun perbaikan katup secara teknis lebih sulit dan dihubungkan dengan angka kegagalan yang tinggi pada anak.

Angka re-operasi pada anak setelah perbaikan katup 5\% sampai 27\%, dibandingkan dengan kasus dewasa hanya $8 \%$ sampai $10 \%$ pada observasi selama 5 tahun. ${ }^{18,19}$ Pada follow-up 52 bulan angka re-operasi mencapai 23,6\% pada pasien di bawah 20 tahun dibandingkan dengan 9,6\% pada pasien yang lebih tua. ${ }^{5}$ Di Amerika Serikat evaluasi keberhasilan operasi katup mitral pada 26 anak selama 18 tahun cukup baik. Tujuh puluh delapan persen anak pada 5 tahun pertama bebas dari tindakan re-operasi dan 65\% memerlukan tindakan re-operasi pada tahun ke-10, sedangkan saat 15 tahun ditemukan $49 \%$ pasien memerlukan tindakan re-operasi. ${ }^{6}$

Pada observasi selama 5 tahun, 254 anak PJR yang menjalani perbaikan katup mitral mempunyai angka kematian pascaoperasi 2,6\%, kematian lebih lanjut $15 \%$, sedangkan angka re-operasi $27 \% .{ }^{4}$ Laporan lain menyebutkan angka kematian pascaoperasi 2,2\% dan kematian lebih lanjut sebesar 2,6\%. ${ }^{10}$ Serangan ulang $\mathrm{DR}$, lesi campuran, penebalan daun katup, disfungsi ventrikel kiri, dan umur muda dihubungkan dengan angka kegagalan yang lebih dini..$^{14,19,20}$ Kelainan mitral pada penyakit reumatik sebaiknya menjalani perbaikan katup kalau teknik memungkinkan untuk mengurangi morbiditas dan meningkatkan survival. ${ }^{4}$ Mitral valve repair dengan aortic valve replacement memberikan outcome yang lebih baik dibandingkan dengan mitral and aortic double replacement, namun mempunyai angka reoperasi yang lebih tinggi. Kejadian tromboemboli juga lebih rendah pada pasien yang menjalani mitral repair dan aortic valve replacement. ${ }^{21,22}$

Fungsi ventrikel kiri pada sesi kasus kami mempunyai rerata normal, walaupun secara klinis sebagian besar pasien bergejla. Tidak terdapat perbedaan antara fungsi ventrikel sebelum dan seminggu setelah operasi, walaupun secara klinis memperlihatkan perbaikan. Penelitian lain menyatakan mitral valve repair pada anak PJR dapat dilakukan dengan aman dan pemeriksaan dimensi ventrikel kiri dan fraksi pemendekan satu minggu dan tiga bulan setelah operasi memperlihatkan perbaikan yang signifikan. ${ }^{11}$ Diperlukan waktu lebih lama untuk kembali normal dan keterlambatan waktu operasi pada anak dengan mitral regurgitasi sampai gejala klinis memberat tidak meningkatkan risiko disfungsi ventrikel di masa datang, namun meningkatkan aritmia. ${ }^{23}$ Perbedaan tersebut memberi kesan bahwa fraksi ejeksi, fraksi pemendekan, dan dimensi ventrikel kiri pada anak PJR sebaiknya tidak dipakai untuk evaluasi jangka pendek pada anak PJR setelah menjalani operasi katup. Penelitian lebih lanjut diperlukan untuk mengetahui parameter terbaik untuk evaluasi jangka pendek berdasarkan pada pemeriksaan ekokardiografi.

Tindakan operasi katup umumnya dilakukan pada PJR kronik, jarang sekali dilakukan pada kasus akut. Seorang anak meninggal setelah operasi karena karditis aktif disertai mitral stenosis berat dengan atrial fibrilasi yang menetap. Operasi katup mitral yang dilaksanakan pada fase akut DR dengan regurgitasi mitral berat dan gagal jantung berat memperlihatkan perbaikan klinis yang memuaskan. ${ }^{24}$ Karditis aktif telah diketahui merupakan kontraindikasi relatif untuk dilakukan pembedahan, namun beberapa laporan menyatakan mitral valve replacement memperlihatkan perbaikan gejala klinis dan merupakan terapi life saving pada kasus karditis aktif dengan gagal jantung persisten karena insufisiensi katup. ${ }^{25}$

\section{Kesimpulan}

Operasi bedah katup pada anak PJR tidak sering dilakukan, namun mempunyai keluaran jangka pendek 
yang baik dengan komplikasi dan kematian yang rendah. Fraksi ejeksi, fraksi pemendekan, dan dimensi akhir diastolik ventrikel kiri tidak dianjurkan dipakai untuk evaluasi jangka pendek fungsi ventrikel kiri. Pemantauan lebih lanjut diperlukan untuk mengetahui outcome jangka panjang.

\section{Ucapan terimakasih}

Kepada Prof. Herry Garna yang telah memberikan masukan dan editing yang bermanfaat.

\section{Daftar pustaka}

1. Madiyono B. Epidemiologi penyakit jantung reumatik di Indonesia. J Kardiol Indones 1995;200:25-33.

2. Duran CM, Gometza B, De Vol EB. Valve repair in rheumatic mitral disease. Circulation 1991;84:125-32.

3. Duran CM, Gometza B, Saad E. Valve repair in rheumatic mitral disease: an unsolved problem. J Card Surg 1994;9:282-5.

4. Yau TM, MD, El-Ghoneimi, YAF, Armstrong S, Ivanov J, David TE. Mitral valve repair and replacement for rheumatic disease. J Thorac Cardiovasc Surg 2000;119:53-61.

5. Choudhary SK, Talwar S, Dubey B, Chopra A, Saxena A, Kumar AS. Mitral valve repair in a predominantly rheumatic population. Longterm results. Tex Heart Inst J. 2001;28:8-15.

6. Hillman ND, Tani LY, Veasy G, Lambert LL, Di Russo GB, Doty DB, dkk. Current status of surgery for rheumatic carditis in children. Ann Thorac Surg 2004;78:1403-8.

7. Carapetis JR, Kilburn CJ, MacDonald KT, Walker AR, Currie BJ. Ten-year follow-up of a cohort with rheumatic heart disease. Aust N Z J Med 1997;27:691-7.

8. Bitar FF, Hayek P, Obeid M, Gharzeddine W, Mikati M, Dbaibo GS. Rheumatic fever in children: a 15-year experience in a developing country. Pediatr Cardiol 2000;21:119-22.

9. Reddy PK, Dharmapuram AK, Swain SK, Ramdoss N, Raghavan SS, Murthy KS. Valve repair in rheumatic heart disease in pediatric age group. Asian Cardiovasc Thorac Ann 2008;16:129-33.

10. Talwar S, Rajesh MR, Subramanian A, Saxena A, Kumar AS. Mitral valve repair in children with rheumatic heart disease. J Thorac Cardiovasc Surg 2005;129:875-9.
11. Kalangos A, Beghetti M, Vala D, Jaeggi E, Kaya G, Karpuz V, dkk. Anterior mitral leaflet prolapse as a primary cause of pure rheumatic mitral insufficiency. Ann Thorac Surg 2000;69:755- 61.

12. Kumar AS, Talwar S, Saxena A, Singh R, Velayoudam D. Results of mitral valve repair in rheumatic mitral regurgitation. Interac Cardiovasc Thorac Surg 2006: 5:356-61.

13. Gillinov AM, Blackstone EH, White J. Durability of combined aortic and mitral valve repair. Ann Thorac Surg 2001;72:20-7.

14. Duran CG, Revuelta JM, Gaite L, Alonso C, Fleitas MG. Stability of mitral reconstructive surgery at 10-12 years for predominantly rheumatic valvular disease. Circulation 1988;78:I91-6.

15. Erez E, Kanter KR, Isom E, Williams WH, Tam VK. Mitral valve replacement in children. J Heart Valve Dis 2003;12:25-9.

16. Kumar AS, Rao PN, Saxena A. Results of mitral valve reconstruction in children with rheumatic heart disease. Ann Thorac Surg 1995;60:1044-7.

17. Enriquez-Sarano M, Schaff HV, Orszulak TA, Tajik AJ, Bailey KR, Frye RL. Valve repair improves the outcome of surgery for mitral regurgitation: a multivariate analysis. Circulation 1995;91:1022-8.

18. Galloway AC, Colvin SB, Baumann FG, Grossi EA, Ribakove GH, Harty S, dkk. A comparison of mitral valve reconstruction with mitral valve replacement: intermediateterm results. Ann Thorac Surg 1989;47:655-62.

19. Aharon AS, Laks H, Drinkwater DC, Chugh R, Gates RN, Grant PW, et al. Early and late results of mitral valve repair in children. J Thorac Cardiovasc Surg 1994; 107:1262-70.

20. Skoularigis J, Sinovich V, Joubert G, Sareli P. Evaluation of the long-term results of mitral valve repair in 254 young patients with rheumatic mitral regurgitation. Circulation 1994;90:167-74.

21. Talwar S, Mathur A, Choudhary SK, Singh R, Kumar AS. Aortic valve replacement with mitral valve repair compared with combined aortic and mitral valve replacement. Ann Thorac Surg 2007;84:1219-25.

22. Lucchese FA, SantÁnna JRM, Kalil RAK, Leite RES, Prates PR, Nesralla IA. Surgery for rheumatic lesions of the cardiac valves in the young. Cardiol Young 1992;2:247-53.

23. Krisnan US, Gersony WM, Berman-Rosenzweig E, Apfel HD. Late left ventricular function after surgery for children with chronic symptomatic mitral regurgitation. Circulation 1997;96:4280-5. 
24. Pomerantzeff PMA, Snitcowsky R, Trevisan IV, Marcial MB, Verginelli G, Jatene AD. Surgical treatment of acute episodes of rheumatic fever. Cardiol Young 1992:2:244-6.
25. Al Kasab S, Al Fagih MR, Shahid M, Habbab M, Al Zaibag M.Valve surgery in acute rheumatic heart disease: One- to 4-year follow-up. Chest 1988; 94:830-3. 